\title{
Intonation across Spanish, in the Tones and Break Indices framework
}

\author{
MARY E. BECKMAN, MANUEL DÍAZ-CAMPOS, JULIA TEVIS \\ MCGORY, TERRELL A. MORGAN
}

\begin{abstract}
This paper describes some of the more salient intonational phenomena of Spanish, and reviews several of the most pressing questions that remain to be addressed before a definitive model of the system can be incorporated into a consensus transcription system for the language. The phenomena reviewed include the metrical underpinnings of the tune, and some of the local tone shapes that are anchored at stressed syllables or at phrase edges in several common intonation contours. The description of known facts is couched in the Autosegmental-Metrical model of intonational phonology, as is the review of outstanding questions. The description is used to motivate the preliminary transcription conventions proposed by the Spanish ToBI development group.
\end{abstract}

\section{Who and what is Sp_ToBI?}

The study of Spanish intonation has a long and illustrious history, beginning with the seminal observations of Navarro Tomás in the first half of the previous century (Navarro Tomás 1918, 1939, 1944). The 1944 monograph, in particular, was monumental for the size of the corpus on which it is based and for its breadth of coverage of the tonemas (i.e., "tones" in the British school sense of the term). Navarro Tomás was also the first researcher to systematically describe some of the major differences among dialects, such as the use in the Caribbean varieties of a steeply falling rather than a rising tonema in pragmatically neutral, syntactically marked yes-no questions. The field has benefited further from two excellent reviews of subsequent literature at quarter-century intervals (Kvavik and Olsen 1974; Alcoba and Murillo 1999), with the first covering more dialects and the second covering more aspects of intonation other than the tonemas. There has been strong interest recently in building on this 
earlier work, recasting it within what has come to be called the AutosegmentalMetrical (AM) model of intonational phonology (Ladd 1996). Work in this framework includes both careful phonetic studies of peak alignment and scaling (e.g. Prieto, Van Santen and Hirschberg 1995), and a comprehensive catalog of tunes (in the AM sense of the term) in several major New World and Peninsular varieties (Sosa 1991, 1999). Hualde (2000) summarizes some of this more recent literature, focusing on three phenomena that are particularly relevant for comparing intonation across the Ibero-Romance languages. In this paper, we will extend Hualde's review, listing other points where there is clear agreement and outlining other questions that need to be addressed before an AM model can be incorporated into a consensus transcription system within the Tones and Break Indices (ToBI) framework (Jun, in press).

We mention a consensus transcription system here because we write this paper as representatives of the Spanish ToBI (Sp_ToBI) development group. The group consists of participants at the first Sp_ToBI workshop ${ }^{1}$ and several others, such as Juan Manuel Sosa, who advised us at various times before and after the meeting. We are an informal coalition of researchers from a wide variety of disciplines who would like to have a consensus annotation system for a large variety of reasons. Before we can build a Sp_ToBI system, we need to achieve a consensus AM analysis of Spanish intonation. We know this will not be easy, for several reasons, not least of which is the sheer size of the problem. Spanish is spoken by more than 350 million people (Grimes 2000) and is a national language in Spain, Mexico, and more than a dozen other major Latin American countries. Therefore, the first question we had to address was: Can we talk meaningfully about "Spanish intonation"? Should we instead be building separate Sp_ToBI conventions for each of the different major dialect areas? Our group decision was to aim at breadth of coverage even if it means sacrificing elegance of analysis. We hope to develop a pan-Spanish ToBI. This means choosing an initial set of tags to capture core phenomena that are shared across dialects, and then extending the system incrementally to capture all meaningful distinctions in each dialect that we study in more depth, even if the distinc-

1. This workshop was held in October, 1999, in the Ohio State University Department of Spanish and Portuguese. It was co-sponsored by the Department of Linguistics, and funded under an Interdisciplinary Seedgrant awarded by the university's Office of Research to Mary Beckman, Marjorie Chan, Terrell Morgan, and Donald Winford. Before the workshop, José Ignacio Hualde prepared materials, including the dialogs from which many of the figures in this paper are taken, so that we could examine and compare recordings of the same sentences uttered in the same contexts by several speakers. Norma Mendoza-Denton took meticulous minutes of our discussion of these utterances at the meeting, and Julia Tevis McGory and Manuel Díaz-Campos used these minutes to make a Sp_ToBI web page that lists the preliminary set of tags which were agreed upon at the meeting, with accompanying speech files illustrating their use. See the Sp_ToBI homepage (http://ling.osu.edu/ tobi/sp-tobi) for these as well as a longer version of this paper. 
tion is not contrastive in every other variety. No doubt some of these tags will seem overly allophonic to speakers of some dialects - i.e., not the broad phonemic transcription that ToBI systems are intended to be (Beckman, Hirschberg, Shattuck-Hufnagel, in press). However, this seems a small price to pay if the tags can capture both the functional parallels and the surface differences that are most likely to cause confusion in conversations between speakers of different dialects.

With that caveat, then, we will motivate our preliminary set of Sp_ToBI tags by reviewing what is known about Spanish intonation. This review is organized as follows. Section 2 describes what is known about Spanish metrical structure and lists the major outstanding questions there. Sections 3 and 4 illustrate some of the tunes that have been observed in declaratives and in interrogatives. Section 5 overviews the problems posed by more global properties - upstep and downstep - and the questions that these phenomena suggest about the phrasing and the analysis of the tune at phrase edges. Section 6 summarizes by listing the conventions that the group agreed upon at the first Sp_ToBI workshop.

\section{The metrical scaffolding: Phrasing and stress}

A first set of questions concerns phrasing. As does every other language that has been described in the ToBI framework, Spanish has tones that are anchored to phrase edges, and the intonational phrases that are marked by the placement of these boundary tones are an important component of the metrical scaffolding of utterances in the language. Figure 1 illustrates, using utterances of a minimal pair from Alcoba and Murillo (1999), contrasting in placement of a medial phrase boundary. After the steep initial rise from Cuando to the end of hubo, there is a marked pitch downtrend in both utterances. In Figure 1a, this downtrend is a steep fall that is interrupted by the continuation rise on the last syllable of hablado, after which a new, more gradual downtrend starts and continues over the entire second clause. In Figure 1b, by contrast, the downtrend is a more gradual one, like the downtrend on Juan se fue in Figure 1a. Moreover, it continues into Juan, where it is again interrupted by a continuation rise, after which the pitch range is low overall. In addition to these pitch correlates of the phrasing, there is also a marked final lengthening that accompanies the continuation rise in each utterance.

The existence of such contrasts in phrasing has long been noted in the literature. For example, the utterance-medial boundary pitch movement in each of the utterances in Figure 1 is one of Navarro Tomás's (1944) five tonemas, the semianticadencia ('half anti-fall' - i.e., 'half rise'). The notion of tonema also captures the fact that the choice of phrase-final pitch configuration is contrastive, as well as the phrase boundary placement. A first goal of any AM 


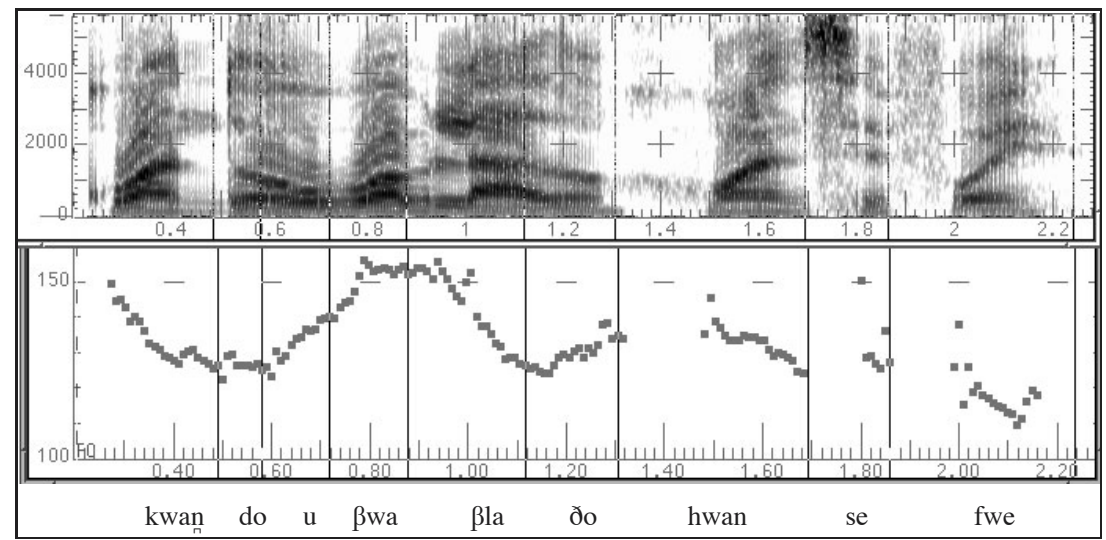

Figure 1a. <alcoba_10a> Spectrogram and fundamental frequency contour for Cuando hubo hablado, Juan se fue. 'When he had spoken, Juan left.' Example (10a) from Alcoba and Murillo (1999), produced by MD, male speaker, Caracas.

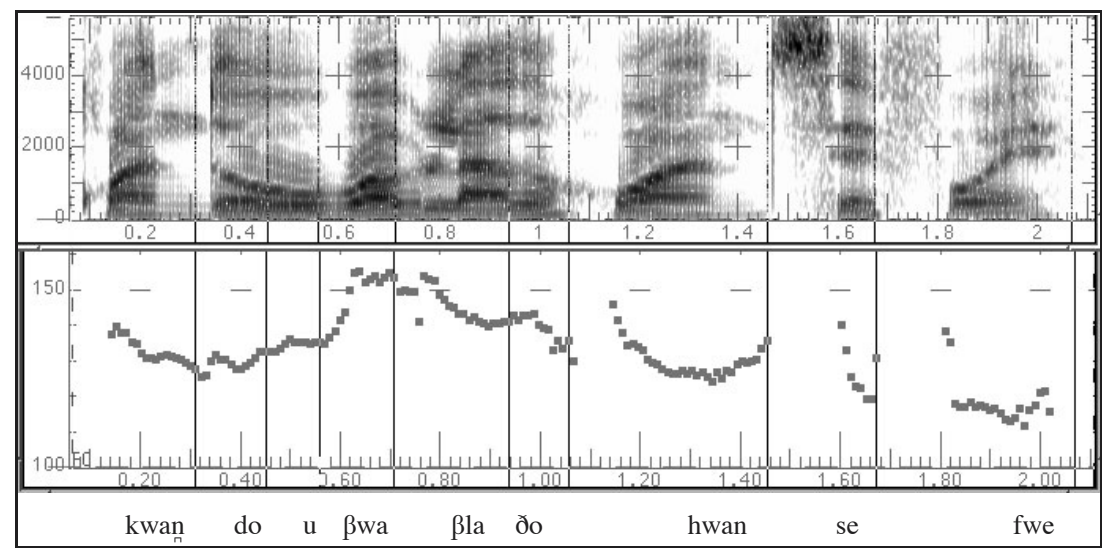

Figure 1b. < alcoba_10b > Cuando hubo hablado Juan, se fue. 'He left after Juan had spoken.’ Example (10)b from Alcoba and Murillo (1999). Speaker MD.

analysis, then, is to analyze these contrasting configurations in terms of autosegmental tone targets. Should we represent the 'half rise' in terms of a mid tone at the edge (M\%) or in terms of a $\mathrm{H} \%$ boundary tone that does not reach the F0 level of the peak on hubo hablabo because of its preceding tonal context? Also, how should the pitch minimum at the beginning of the "half rise" be analyzed? A closely related question is whether there is just one level of intonational phrasing, as in Japanese (Venditti 1997), or two levels, as in Greek (Ar- 
vaniti and Baltazani, in press). Sosa $(1991,1999)$ argues that the inventory and distribution of tones support only one level of intonational phrasing, whereas Nibert (2000) and Hualde (2000) argue for two levels, but on somewhat different grounds. The arguments for the different analyses hinge on claims about how pitch range effects and the amount of final lengthening interact with the choice of tones near the phrase boundary. However, the evidence to support any of these claims is still inconclusive. Therefore, the Sp_ToBI group opted for a compromise analysis, by which we mark boundary tones only for a single level of intonational phrasing, but leave gaps for a possible intermediate level in the hierarchy of break index values. ${ }^{2}$ We will return to this issue in Section 5, after reviewing the other metrical positions where tones are associated internally to the intonational phrase.

A second set of questions involves the landmarks for tone association within the intonational phrase. All dialects of Spanish have lexical stress, and it is impossible to talk about Spanish intonation without reference to this prosodic construct. Location of stress is contrastive, as in Italian. For example, numero 'I enumerate', which has the "default" penultimate stress, contrasts both with número 'number' and with numeró 'she enumerated'. As in other languages where stress is a useful prosodic descriptor, stress can be defined as a metrical position that is marked phonologically and phonetically by the congruence of prominence-lending properties on several autosegmental tiers, including the tone tier. For example, vowels in stressed syllables tend to be phonetically longer than vowels in unstressed syllables in the same position in the phrase (see, inter alia, Quilis 1971, Face 1999). A phonological corollary of this durational effect is the syllabic parsing of vowels in sequence. For example, in Figure 1, the /o/ in the final unstressed syllable of hubo merges with the word-initial /a/ of hablado to yield [ $\beta \mathrm{wa}$ ]. The single most reliable phonological marker of lexical stress, however, is the licensing of tone (Quilis 1971). When a word is produced as a complete utterance, the intonation contour of the utterance has at least one tone target that is anchored to the stressed syllable. Following the usage of Bolinger (1958), Bolinger and Hodapp (1961), Pierrehumbert (1980), and all subsequent work in the Autosegmental-Metrical framework (see Ladd 1996), we will call a tone or tone sequence that is anchored to a stressed syllable a "pitch accent". A word containing a stressed syllable that is associated to a pitch accent is then accented.

This phonological marker of stress is illustrated in Figure 2, which shows productions of the sentence Le dieron el número de vuelo. produced by two male speakers in simulated response to ¿Qué le dieron a María cuando fue al aeropuerto?, a question invoking a broad focus of attention on the phrase $\mathrm{el}$

2. Break indices are numbers corresponding to the degree of perceived disjuncture at each word edge. See section 6. 


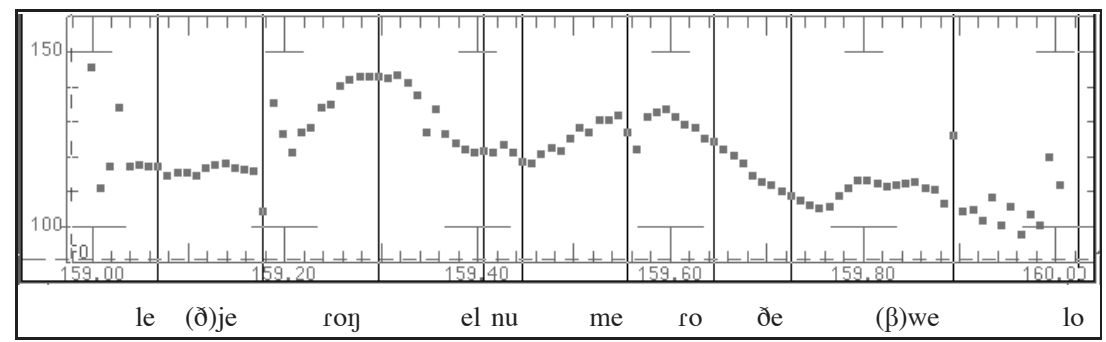

Figure $2 a .<\mathrm{md}$ s $1>$ Le dieron el número de vuelo. 'They gave her the flight number.' Response to ¿Qué le dieron a María cuando fue al aeropuerto? 'What did they give María when she went to the airport?' Speaker MD, Venezuelan Spanish. Cursors demarcate syllable boundaries.

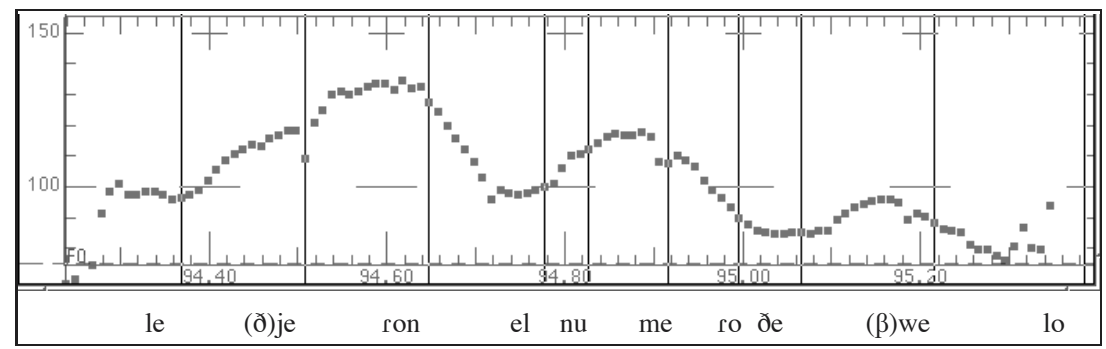

Figure $2 b .<$ jih_o1 $>$ Same sentence and context as in Figure 2a, produced by JH, male speaker, Castilian Spanish.

número del vuelo. The speakers are from different dialect areas. However, both produce a rise to a pitch peak around the stressed syllable in each of dieron, numero, and vuelo. Note that the timing of the rise differs, both between speakers and between positions in the sentence for the Venezuelan speaker. That is, where the Castilian speaker begins the rise at the onset of the rhyme, the Venezuelan speaker shows an extended trough across the stressed syllable in dieron and número. For the sentence-final vuelo, however, the Venezuelan rise looks like the Castilian accent pattern, with the rise starting at the beginning of the rhyme in the stressed syllable and ending well before the end of the syllable. How can we account for the positional difference within the AM framework?

Answering this question requires that we simultaneously address three other questions, all of which involve the issue of possible tonal hallmarks of a higherlevel stress contrast, independent of the contrast between stressed and unstressed syllables within a word. The first of these questions concerns the notion of "sentence stress" or prominence by position. As in many "scram- 
bling" languages, including Finnish (Välimaa-Blum 1988) and Serbian (Godjevac 2000), word order as well as ellipsis is strongly influenced by informational structure. The nominative argument of a verb, for example, can be elided completely (i.e., Spanish is a "pro-drop" language), but if it is expressed by a noun phrase, that noun phrase can come either before the verb (as in Figure 1a) or after it (as in Figure 1b). The choice of word order seems to be closely related to the metrical organization. That is, other things being equal, final position is metrically strong (see, e.g., Contreras 1980), and we will refer to an accented word in this position as bearing the "nuclear accent" of the phrase. Many other Romance languages differentiate nuclear position from other less prominent positions by the choice of pitch accent type. For example, Frota (this issue) and D'Imperio (this issue) describe the broad focus declarative patterns for European Portuguese and Italian in terms of a peak accent $\left(\mathrm{L}+\mathrm{H}^{*}\right.$ or $\left.\mathrm{H}^{*}\right)$ on non-final words, but a $\mathrm{H}+\mathrm{L}^{*}$ accent (with pitch falling onto the accented syllable) for the word in nuclear position. Could the difference between the accents on dieron and vuelo in Figure 2a be a similar categorical marker of this positional contrast?

The second and third questions involve the notion of focus. Several other Romance languages have a mechanism for highlighting a word in metalinguistic corrections by the use of a special "narrow focus" pitch accent type. For example, Frota (this issue) describes a contrast in European Portuguese between $\mathrm{H}+\mathrm{L}^{*}$ for nuclear accents in broad focus utterances and $\mathrm{H}^{*}+\mathrm{L}$ (a later fall that positions the peak more nearly in the middle of the accented syllable) for a word in narrow focus. D'Imperio (this issue) describes a similar contrast for Neapolitan Italian between $\mathrm{H}+\mathrm{L}^{*}$ for broad focus and $\mathrm{L}+\mathrm{H}^{*}$ for narrow focus. In both of these languages, the marking of narrow focus on a non-final word is accomplished by the use of the special focal accent, accompanied by "deaccenting" - i.e., the suppression of accents on any following words within the same intonational phrase. Is there a comparable differentiation between focal and non-focal accent types in Spanish? Also, is there deaccenting of post-focal material when the context calls for narrow focus on a non-final word? We will address these questions next, beginning with those that involve the number of distinct pitch accent types.

\section{Peak accents and falling accents in some declarative contours}

Contreras (1977) proposes a special "melodic peak" for the accent of any constituent in "rheme" position, whether or not the rheme is also sentence-final. ${ }^{3}$

3. The Prague school account of information structure partitions a sentence into "theme" (what the speaker is talking about) and "rheme" (what the speaker says about the theme). Contre- 
This suggests that the tonal hallmarks of early narrow focus are similar to those of nuclear position, perhaps both showing the early peak of the accent on vuelo in Figure 2. Figure 3a lends support to this idea. Here the word número is in narrow focus, and it has an earlier rise than in the broad-focus utterance of the same sentence by the same speaker in Figure 2a. The Sp_ToBI conventions follow Contreras in representing both of these instances of "melodic peak" with $\mathrm{L}+\mathrm{H}^{*}$ (i.e., a rise to a peak that is anchored in the stressed syllable) and differentiating this type from $\mathrm{L}^{*}+\mathrm{H}$ for the earlier rise on dieron and número in Figure 2a, as shown in (1a). Note that the transcription also marks downstep, the progressive compression of pitch range that lowers each subsequent peak relative to the previous one, using !, the downstep diacritic that has become standard in the ToBI framework. That is, $\mathrm{L}^{*}+! \mathrm{H}$ is the same as $\mathrm{L}^{*}+\mathrm{H}$, with peak lowered due to downstep, as shown in (1b).

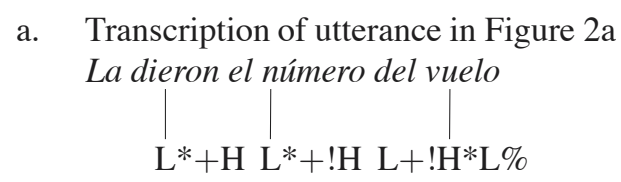

b. Schematic representation of downstep Le dieron el número del vuelo

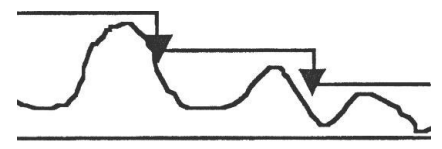

Our choice of two different AM representations for the early and late rise follows Sosa (1999), who shows examples of utterances of the sentence in Figure 2a produced by other speakers of the same dialect. There is a suggestion that this rapid succession of rises in a broad focus sentence gives a sense of lively engagement or emphasis (see Figure 2-27 on p. 129 of the 1999 monograph) and that in a more neutral case, there might be no discernible valley between the last two accents, requiring an alternative analysis for the nuclear accent, possibly as a L* (see Figure 2-3 on p. 110 of Sosa (1999) and Figure 5 below). Our decision to differentiate a late-rising $\mathrm{L}^{*}+\mathrm{H}$ prenuclear accent from an early-rising $\mathrm{L}+\mathrm{H}^{*}$ nuclear or focal accent thus is based on the clear evidence for such a difference in Caracas utterances such as Figures 2a and 3a. Data in Willis (2000) suggest that Dominican Spanish also requires this distinction.

At the Sp_ToBI workshop, we decided to apply the $\mathrm{L}^{*}+\mathrm{H}$ label to many prenuclear rising accents in Castilian Spanish as well. For example, in tagging the utterance in Figure 3c, we marked the accent on dieron as $\mathrm{L}^{*}+\mathrm{H}$ to capture

ras follows Halliday (1967) in assuming that this information structure maps directly onto intonational structure in languages such as Spanish and English. 
the fact that the inflection point that marks the end of the rise on dieron (and the beginning of the rise on el numero) is at the end of the unstressed second syllable of the word. The rise on dieron in Figure 3b, by contrast, culminates in a peak before the end of the stressed first syllable. Other researchers, however, have argued against this distinction for at least Castilian and Mexican Spanish. For example, Garrido et al. (1995) and Prieto (1998) claim that there is no categorical difference between the prenuclear and the nuclear accent types, and attribute the observed differences in peak timing to tonal crowding. The accent is simply a rise, with the $\mathrm{L}$ anchored to the beginning of the stressed syllable and the timing of the $\mathrm{H}$ determined by other factors, such as tonal crowding. In nuclear position, for example, the peak is pushed back into the stressed syllable in order to make room for both it and the upcoming $\mathrm{L} \%$ tone to be realized. A possible argument for positing two distinct rising accent types even for Castilian Spanish is that the variant with the early peak seems to be found in many non-final words under narrow focus (see Face 2001). Nibert (2000) makes the following counter-argument. She notes that rises following a focal accent are often reduced (as in vuelo in Figure 3a) or even eliminated (as in número in Figure $3 \mathrm{~b}$ ). Therefore, she says, there must be another tone inserted at the end of the word here, a $\mathrm{L}^{-}$phrase accent, of the same sort that we see after the accent on a word with early narrow focus in English declarative utterances. ${ }^{4}$ The phrase accent compresses the pitch range so that post-focal rises are reduced, or perhaps even deleted (as in Portuguese or Italian "deaccenting"). The earlier peak on a pre-nuclear word under narrow focus, then, can be attributed to the same tonal crowding that Garrido et al. (1995) and Prieto (1998) invoke to explain the earlier peak on the word in nuclear position. On the principle that a pan-Spanish ToBI should over-specify rather than under-specify, however, the Sp_ToBI group recommended differentiating the tags for early and late peaks even for those Peninsular varieties where the difference may be allophonic.

\footnotetext{
4. She also claims that the $\mathrm{L}^{-}$marks a phrase boundary at a lower level of intonational phrasing, but this claim must be evaluated separately, since phrase accents in many languages can occur medially, with following pitch accents reduced but not suppressed (see, e.g., Bruce 1977; D'Imperio, this issue; Grice et al. 2000; Gussenhoven 2000). We will return to this issue in Section 5.
} 


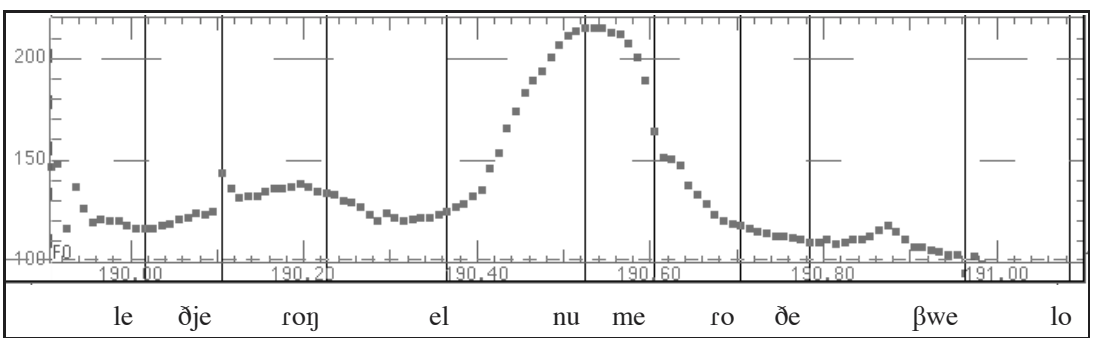

Figure 3a. <md_s3 $>$ No, le dieron el número de vuelo. 'No. They gave her the flight number.' uttered in simulated response to ¿Le dieron la hora del vuelo? 'Did they give her the flight time?' Speaker MD, Venezuelan Spanish.

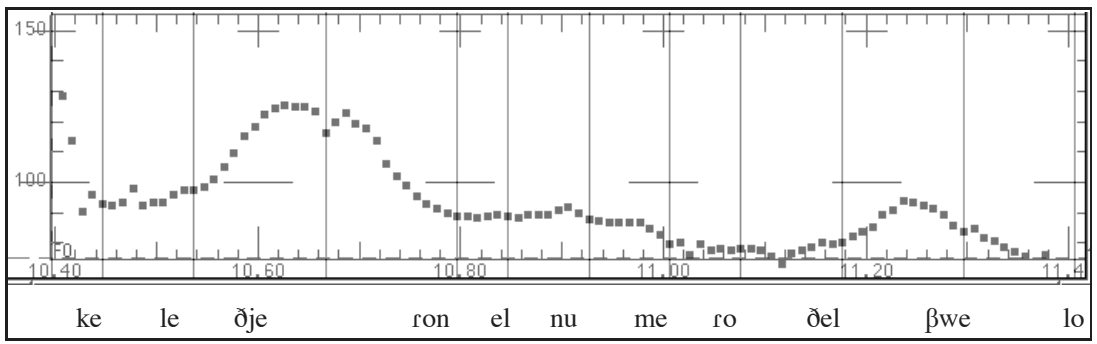

Figure 3b. <jih_05> No, que le dieron el número del vuelo. 'No, (I said) that they gave her the flight number.' Response to ¿Dices que le pidieron el número de vuelo? 'Did you say they asked her for the flight number?' Speaker JH, Castilian Spanish.

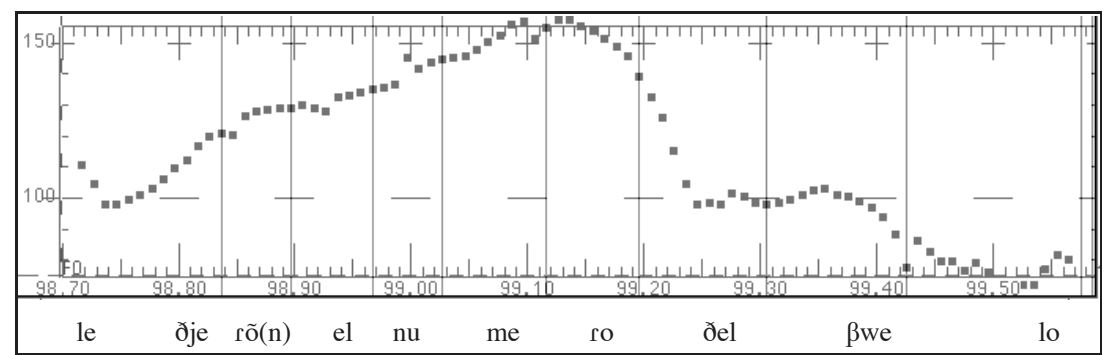

Figure 3c. <jih_o2> Le dieron el número del vuelo. 'They gave her the flight number.' Response to ¿Le dieron el número de vuelo o el número de asiento? 'Did they give her the flight number or the seat number?' Speaker JH.

Further justification for this transparently surface transcription is our analysis of the intonation contour illustrated in Figure 4a. The full context is given in (2), with the target sequence underlined. We call this the "redundancy contour" 
because the pragmatic effect is: "This information is redundant. It is something that I know you know, and think you could have thought of yourself as the motivation or explanation for this opinion or observation."

Dialog for Figure 4a.

A: A mí me parece normal que todo empiece a su hora. 'I think it is normal for everything to start on time.'

B: Bueno, sí, normal, para la universidad alemana. No para cualquier sitio, o también puede ser quizá normal para un alumno de alemán.

'Well, yeah, normal for a German university. Not for just any place. Or maybe normal for a student of German.'

A: Eso, para un alumno de alemán. 'That's right, for a student of German.'

The features of interest in this redundancy contour are the timing of the first rise and the shape of the transition to the second rise. The first rise culminates in a peak during the stressed second syllable of normal. From this peak value there is a very gradual, smooth fall to the beginning of the word in nuclear position, with no evidence of a suppressed peak accent on the intervening universidad. That is, even though the rise aligns to the stressed syllable in a way that is more similar to the rise in dieron in Figure $3 b$ than to the rise in the same position in Figure 3c, the subsequent fall differs markedly from the steep fall to the compressed pitch range on número in Figure 3b. Our tentative analysis is that the redundancy contour is an intonational idiom consisting of a pair of $\mathrm{L}+\mathrm{H}^{*}$ accents at the beginning and end of the target phrase, with no intervening accent. (For comparison, Figure $4 \mathrm{~b}$ shows another utterance of para la universidad alemana, with universidad accented.) If we are correct about the deaccenting of universidad in Figure 4a, this contour would be an unambiguous case of an early rise that cannot be explained by tonal crowding even in Castilian Spanish.

One final puzzle is the shape and timing of the rises on non-final número in Figure $3 c$ and universidad in Figure $4 b$. In neither of these cases is the word in narrow focus. Rather, in Figure $3 \mathrm{c}$, there is a narrow focus on the following vuelo, and if either word in Figure $4 \mathrm{~b}$ has narrow focus, it would be alemana. That is, it seems more plausible that the speaker assumed the books would be going to some university than that they would be going to something German. The segmental allophony in Figure $4 \mathrm{~b}$ suggests an explanation for the rise alignment pattern. The /d/ at the end of universidad is devoiced. Many of the participants at the Sp_ToBI workshop perceived this $[\theta]$ as a cue to the end of some kind of prosodic unit. The speaker himself has "always thought that this was a word-level phenomenon in my dialect" (personal communication), but if 


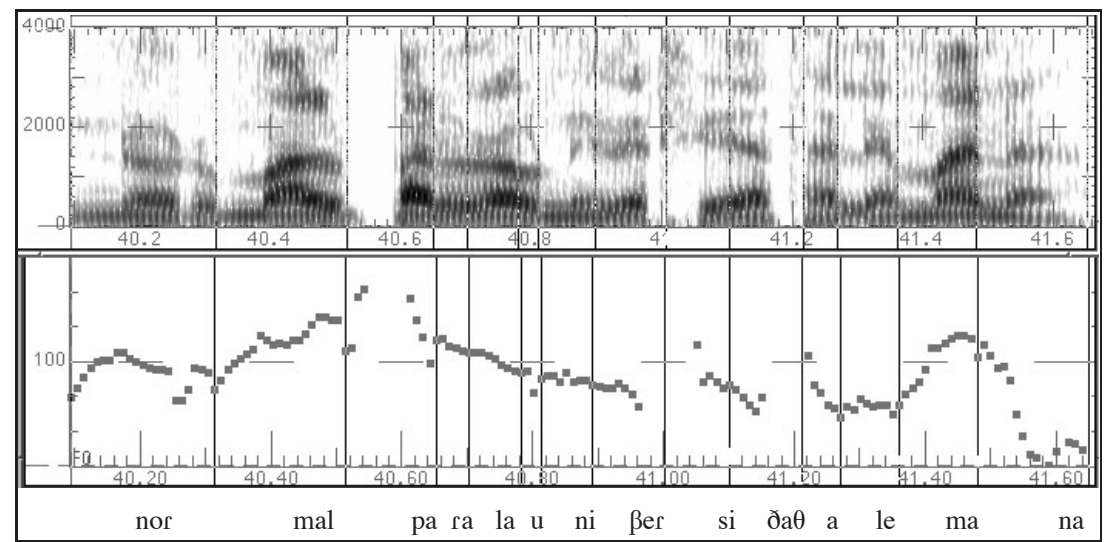

Figure 4a. < jihf4> (Bueno, sí,) normal, para la universidad alemana ... '(Yeah, well,) normal for a German university ....' See (2) in text for context. Speaker JH, Castilian Spanish.

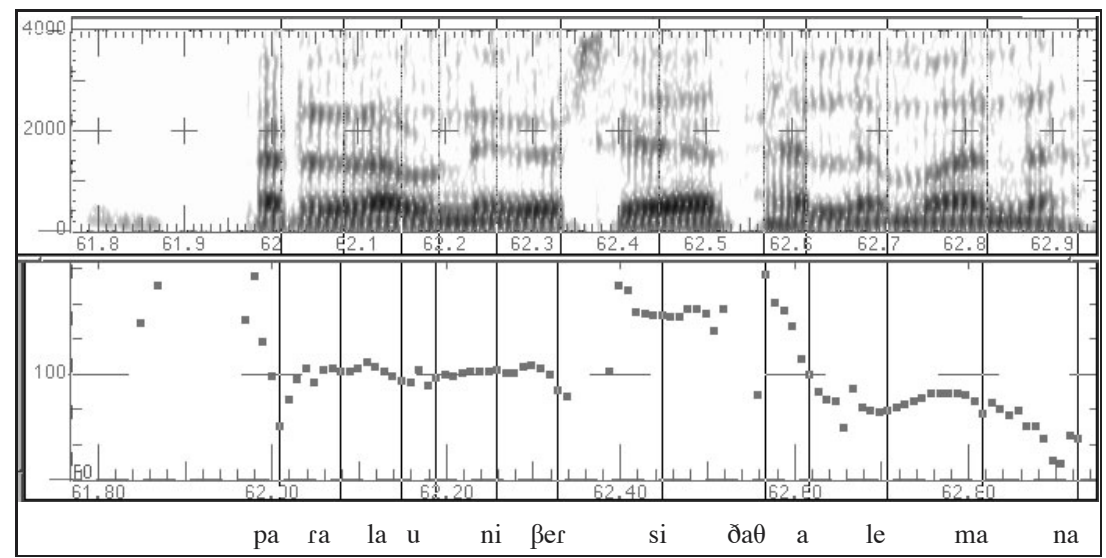

Figure 4b. <jih_nf4> Para la universidad alemana. 'To the German university.' Response to ¿Para quién es este libro? 'Where are these books going?' Speaker $\mathrm{JH}$, Castilian Spanish.

the relevant prosodic unit is some kind of intonational phrase, then the medial word in the sentence is final in the phrase and the peak is early because this is in nuclear position. If the phrasing is the same in Figure 3c, then this might explain the percept of narrow focus on vuelo rather than on numero. That is, the narrow focus cannot be signaled by the peak alignment on vuelo since it would have an early peak in any case, due to its utterance-final position. Putting it in 
an intonational phrase all by itself might be an alternative focusing device, as suggested by Face (this issue). This analysis also would help explain another obvious difference between Figure $3 \mathrm{c}$ and the two broad focus utterances in Figure 2 - namely, presence versus absence of a discernible valley between the rise on dieron and the rise on número. However, these explanations invoke the global phenomenon of upstep, so we defer the discussion until Section 4, and turn to another type that shows no discernible valley between two accents.

An example of this type is the nuclear accent in the clause in Figure 1a. After the prenuclear rise on hubo, pitch remains high for the brief space of the merged syllable at the word boundary, and then falls steeply after the /b/ in hablado. The utterance in Figure 5 shows an even clearer example. After the prenuclear rise on dialectos, pitch remains high and level through the two function words, and then falls abruptly onto the stressed syllable of lengua. At the Sp_ToBI workshop, we transcribed another example of this nuclear configuration in an utterance produced by a Castilian speaker. To account for such cases of early fall with no preceding valley, we proposed a $\mathrm{H}+\mathrm{L}^{*}$ nuclear pitch accent. This analysis identifies the pitch accents in these two utterances with the broad focus nuclear pitch accent of European Portuguese (Frota, this issue) and of Italian (D'Imperio, this issue). The analysis is compatible with the pitch pattern in several of the utterances that Sosa (1999) transcribes as having a L* nuclear accent, including the utterance (by a Caracas speaker) of Es negra. in Figure 2.11 (p. 116), where there is a pitch fall from the unaccented $E s$ into the stressed syllable of negra. ${ }^{5}$ McGory and Díaz-Campos (2000b) also found $\mathrm{H}+\mathrm{L}^{*}$ in utterances produced by speakers from all major dialect areas. They examined the tunes in an extended narrative read by two speakers each from Argentina, Chile, Colombia, Venezuela, Costa Rica, Puerto Rico, Mexico, and central Spain. They were conservative in tagging pitch accent types, distinguishing among early rises $\left(\mathrm{L}+\mathrm{H}^{*}\right)$, late rises $\left(\mathrm{L}^{*}+\mathrm{H}\right)$, and early falls $\left(\mathrm{H}+\mathrm{L}^{*}\right)$, but also having a fourth category of "NO" for cases where there was no easily categorized pitch movement around the stressed syllable. That is, they marked $\mathrm{H}+\mathrm{L}^{*}$ only in such clear cases as the utterance in Figure 5, which is an example from their study. The passage they examined is part of the Morgan (2000) database, and consists of five long broad-focus sentences, such as Hay mas de trescientos millones de personas que hablan español, principal-

5. This utterance is also shown as Figure 12 in Sosa (1991: 102), where it makes a minimal pair with both an interrogative and with another declarative (in Figures 20 and 19 on p. 107). The other declarative shows a rise in pitch from $E s$ to a peak on the stressed syllable of negra, which we would transcribe as $\mathrm{L}+\mathrm{H}^{*}$. The second author of this paper, who also is a Caracas speaker, describes the contrast between the two declaratives as broad focus assertion versus narrow focus correction. The $\mathrm{H}+\mathrm{L} *$ in Figure 12 might be appropriate in response to 'Let me get your suitcase from the rack. What color is it?' whereas the $\mathrm{L}+\mathrm{H}^{*}$ in Figure 19 would be in response to 'Is your suitcase this brown one?' 


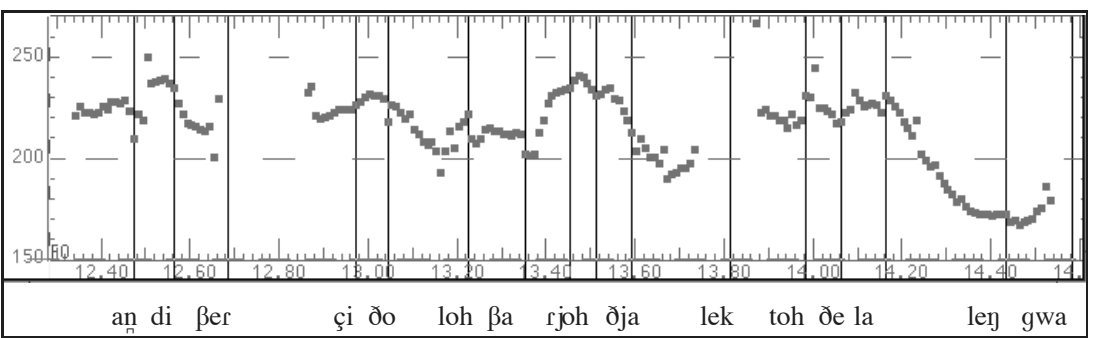

Figure 5. Extract from $<300$.CH.F $>$.. han divergido los varios dialectos de la lengua. '... there have emerged various distinct dialects of the language.' Produced by FB, female speaker, Chile.

mente en España y Latinoamérica. 'Spanish is spoken by more than 300 million people, primarily in Spain and Latin America.' and Por razones históricas y geográficas, han divergido los varios dialectos de la lengua. 'Historical and geographical factors have led to the emergence of various distinct dialects.' These sentences were pronounced as several intonational phrases by all of the speakers, and the $\mathrm{H}+\mathrm{L}^{*}$ type was used as the nuclear accent in at least one intonational phrase by speakers of every dialect other than Colombia and Costa Rica. Moreover, it was the nuclear accent type in $70 \%$ of the phrases produced by the two speakers from Chile. Further study of more speakers from each of these dialect areas and of the analogous patterns in Portuguese and Italian speakers may illuminate the razones históricas y geográficas for the different distributions that McGory and Díaz-Campos found.

\section{Question contours and upstep}

The fundamental frequency contours that we discussed in the previous section suggest that there are subtle differences across dialects in the tunes for declarative utterances, which may be the source of some of the disagreement among different AM analyses of the Spanish intonation system. The differences for interrogative tunes are much less subtle, particularly when Caribbean dialects are included in the comparison, as in Figure 6. The figure shows yes/no questions, with and without syntactic inversion. In Figure 6a the Castilian Spanish speaker produces a clear example of how Alcoba and Murrillo transcribe Navarro Tomás's anticadencia ('full rise') for their Example (16b). After the late peak of the rising accent on the initial word, pitch falls steadily across the medial word to reach a minimum value that extends across the stressed syllable in mañana, before rising again very sharply at the phrase boundary. In Figure $6 \mathrm{~b}$, the Venezuelan speaker produces the same $\mathrm{L}^{*}+\mathrm{H}$ rising accent on 
viene, albeit with the even later rise that is characteristic of this dialect. After that, however, pitch first falls sharply and then becomes almost the mirror image of the anticadencia. There is low pitch starting at the stressed syllable of María, then a rise to a brief "shoulder" on the first syllable of mañana, another rise to a high peak in the middle of the stressed syllable, and then a steep fall that levels out at the boundary. In the question without syntactic inversion in Figure 6c, the speaker again produces low pitch over María, followed by a rise over the stressed syllable of viene, leveling out to a more pronounced shoulder, which is followed again by a peak in the middle of the stressed syllable of mañana, and a sharply falling boundary pitch movement. The two utterances differ in informational structure as well as word order. The utterance in Figure $6 \mathrm{~b}$ is a fairly neutral broad-focus question, whereas the utterance in Figure $6 \mathrm{c}$ specifically queries about the time.

At the Sp_ToBI workshop, we discussed the interrogative tunes produced by our two Venezuelan speakers, but did not have time to look closely at the interrogatives produced by $\mathrm{JH}$. Therefore, there is no Sp_ToBI proposal for how to transcribe the nuclear accent on mañana in Figure 6a. Given how low and level the pitch is throughout the stressed syllable of mañana, Sosa's (1991) transcription of $\mathrm{L}^{*}$ for the very similar Mexican interrogative tune in his Figure 25 on p. 174 is appealing. Without a more extensive investigation of how the tune is realized on other word sequences, however, we cannot rule out Alcoba and Murillo's (1999) analysis of the tune, which tags the nuclear accent as a downstepped target (i.e., ! $\mathrm{H}^{*}$ in AM notation). Also, while there is clearly a high boundary tone ending the utterance, we cannot tell why this 'full rise' ends at a higher level than the two 'half rises' in Figure 1. If the $\mathrm{H}+\mathrm{L} *$ nuclear accent in Figure 1 triggers downstep, then the $\mathrm{L}^{*}$ or $! \mathrm{H}^{*}$ here does not, and the contrast would be between a downstepped !H\% in Figure 1, as schematized in (3a), and the 'normal' level for a H\% in Figure 6a. Alternatively, if there is a $\mathrm{H}^{-}$phrase accent before the boundary tone in Figure $6 \mathrm{a}$, as suggested by Nibert (2000) for similar tunes in her study, that phrase accent would trigger upstep and the contrast is between a 'normal' $\mathrm{H} \%$ in Figure 1, and an upstepped ${ }_{i} \mathrm{H} \%$ in Figure 6a, as schematized in (3b). (Note the diacritic $i$, the opposite of the downstep diacritic, which the Sp_ToBI conventions specify for marking upstep. Upstep is the opposite of downstep, an expansion of the pitch range that raises subsequent tones.) Rather than commit prematurely to either analysis, the Sp_ToBI group chose to adopt, as a temporary measure, a mid-level boundary tone tag $(\mathrm{M} \%)$ to differentiate the half rise from the full rise. This decision will be discussed further in Section 5 . 


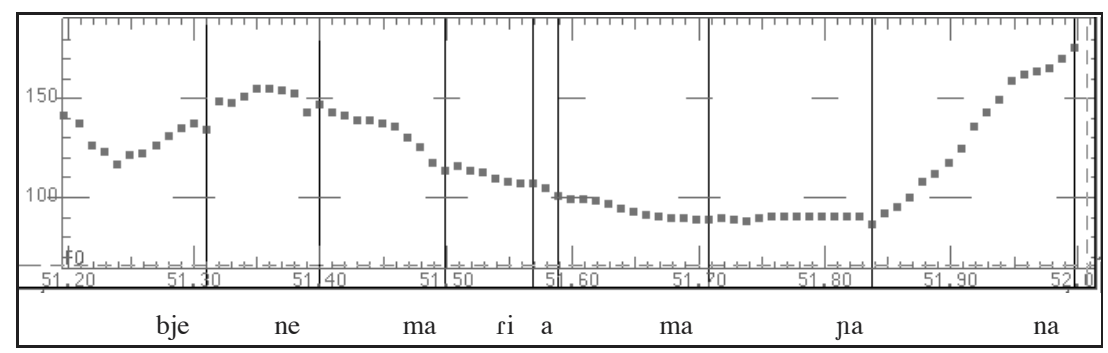

Figure 6a. <ji_q1> ¿Viene María mañana? 'Is Maria coming tomorrow?' Yes-no question with syntactic inversion. Possibly broad focus? Speaker JH, Castilian Spanish.

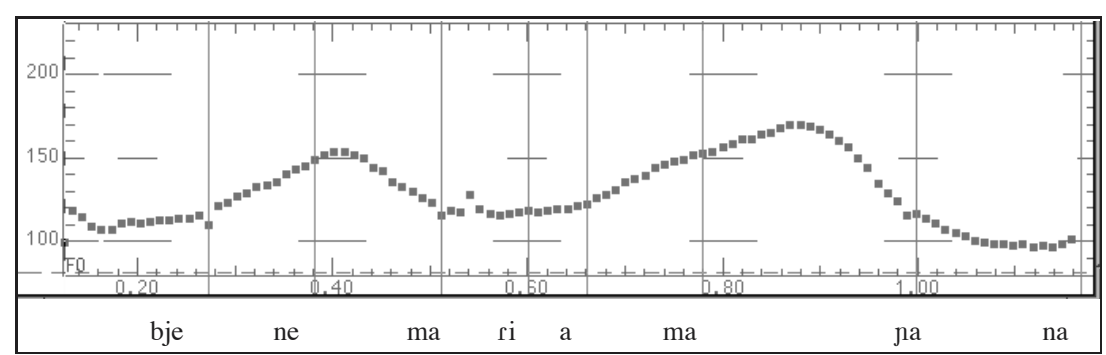

Figure 6b. <c_q1> ¿Viene María mañana? 'Is Maria coming tomorrow?' Yes-no question with syntactic inversion, as in Figure $6 \mathrm{a}$, produced by $\mathrm{CC}$, male speaker, Caracas. Perceived by MD as "a normal question, out of the blue" with no special narrow focus on verb, subject, or adverb.

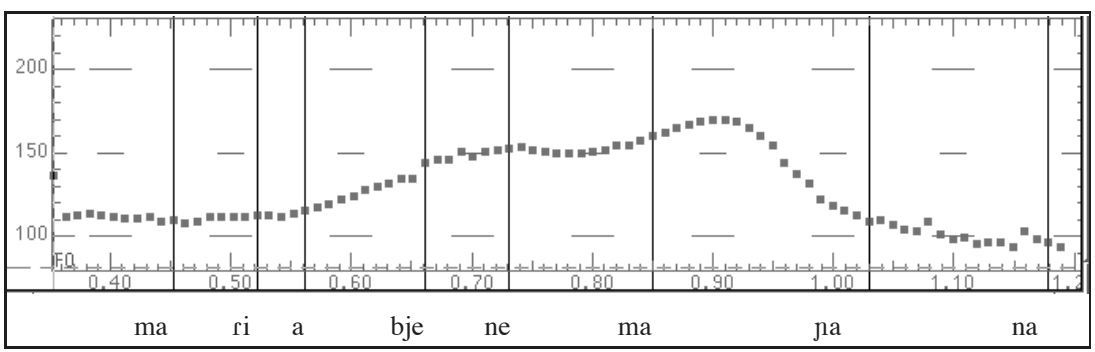

Figure 6c. <c_q2> ¿María viene mañana? 'Maria's coming tomorrow?' Speaker CC, Caracas. Perceived by MD as a confirmation question with narrow focus on mañana. "In this case you want to check if it is tomorrow that María is coming." 


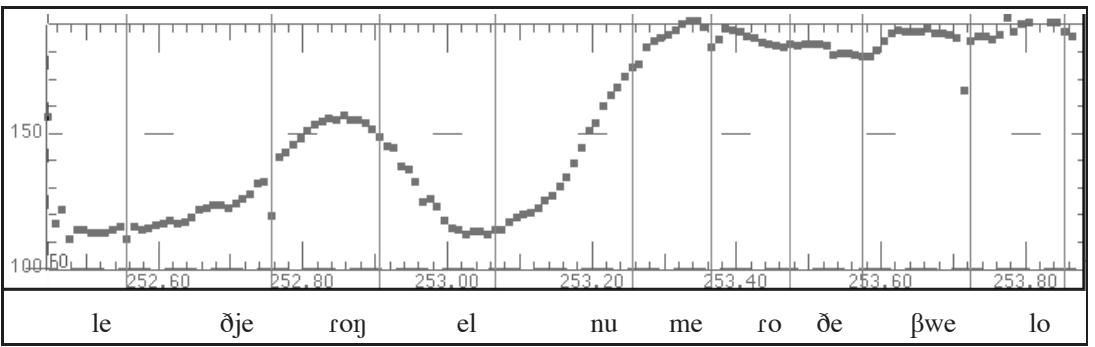

Figure 7a. $<$ md_yn3> ¿Le dieron el número de vuelo? 'They gave him the flight number?' Speaker MD, Caracas. Confirmation question with narrow focus on número. (Compare Figure 3a.)

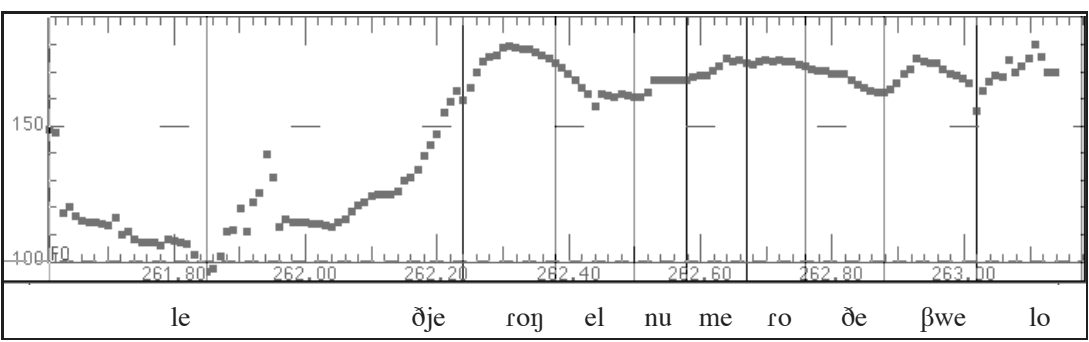

Figure $7 b .<\mathrm{md}$ yn $4>$ ¿Le dieron el número de vuelo? 'They gave him the flight number?' Speaker MD, Caracas. Perceived by MD as having narrow focus on dieron.

a. Downstep of $\mathrm{H} \%$ after $\mathrm{H}+\mathrm{L}^{*}$

Cuando hubo hablado...

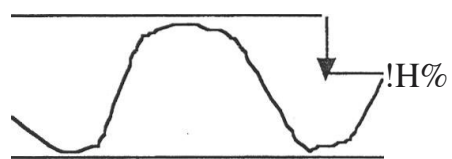

b. Upstep of $\mathrm{H} \%$ after $\mathrm{H}^{-}$

¿Viene María mañana?

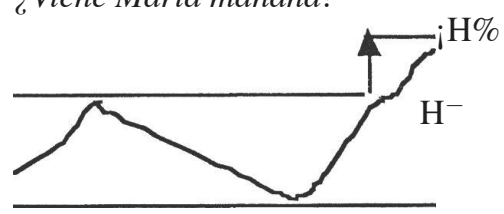

The issue of upstep also arose in our discussion of the Venezuelan yes/no questions. At the workshop, we identified the pitch rises over María viene in Figure 
$6 \mathrm{~b}$ and over viene mañana in Figure $6 \mathrm{c}$ with a functionally different but phonetically comparable pattern in our Castilian speaker's productions - namely, the rise over Le dieron el número in Figure 3c. The analysis we proposed in each case was a sequence of two rising accents, with upstep, as shown in (4). This analysis is very transparently motivated in Figure 6c. Note first the small dip that interrupts the rise on the first syllable of mañana in Figure $6 \mathrm{c}$. We interpret this dip as evidence of a $\mathrm{L}$ target for a $\mathrm{L}+\mathrm{H}^{*}$ nuclear accent on mañana. We interpret the fact that this $\mathrm{L}$ is nearly as high as the $\mathrm{H}$ of the rising accent on viene as evidence that the speaker has raised his backdrop pitch range, so that the "floor" of his voice after the first accent is nearly at the same level as the "ceiling" during the first accent. The same interpretation works for the momentary interruption of the rise during the first part of Figure $3 \mathrm{c}$. The speaker raised the overall pitch range after the $\mathrm{L}^{*}+\mathrm{H}$ accent on dieron, so that the initial target of the $\mathrm{L}+\mathrm{H}^{*}$ nuclear accent on número is at the same level as the peak on dieron. The exact timing of the peak on número is further obscured by the rise to the following $\mathrm{H} \%$ boundary tone at the phrase edge before the focused vuelo. Hualde (2000) suggests that upstep in declarative utterances in Castilian Spanish is used to partition the sentence into theme and rheme. In Figure 3c, this analysis is particularly attractive, given the focus structure that we specified by the elicitation context. By this analysis, then, the modality of the Caribbean Spanish interrogative is signaled in the same way that the theme is differentiated from the rheme in the Castilian Spanish declarative.

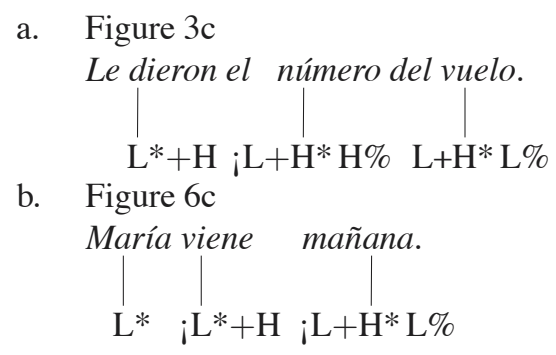

The idea that there is upstep on mañana in Figures $6 \mathrm{~b}$ and $6 \mathrm{c}$ is in accord with Sosa's $(1991,1999)$ analysis of such "circumflex" Caribbean interrogative contours. That is, he too describes such peaks as upstepped. However, his transcription differs from ours in being considerably more abstract. Rather than mark the upstep directly he attributes it to the choice of pitch accent type. The nuclear accent in utterances such as Figure $6 b$ then is " $\mathrm{H}+\mathrm{H}^{*}$ ", with the leading $\mathrm{H}$ tone not realized directly as a target, but functioning merely to upstep the following peak. Hualde (2000) proposes a third alternative, which is as abstract as Sosa's. He notes that Nibert (2000) accounts for some boundary pitch 
movements by positing a $\mathrm{H}^{-}$phrase accent that upsteps the following boundary tone, as in the standard AM analysis of the mainstream North American and standard Southern British English system (Pierrehumbert 1980; Beckman, Hirschberg, and Shattuck-Hufnagel, in press). Nibert's upstep trigger is meant to explain local patterns at phrase edges, but Hualde proposes that it also triggers upstep over successive accents prior to the boundary. If we adopt Hualde's proposal, we can account both for the upstep from Le dieron to número in Figure $3 \mathrm{c}$ and for the further rise to an especially high pitch level just before del vuelo. Space limitations preclude a full discussion of the substantive differences among these proposed analyses of upstep, so here we point out merely that the analysis of the Venezuelan interrogative contour needs to be able to account both for the raised peak on mañana and for the pitch target at the following boundary, which is lower than the initial target of the $\mathrm{L} *+\mathrm{H}$ accent on viene. We proposed to transcribe the boundary tone as L\%, as does Sosa. Some other Caracas questions that we examined show a leveling off of pitch rather than this steep fall. Figure 7 shows two such examples. If we adopt Nibert's notion of a $\mathrm{H}^{-}$versus $\mathrm{L}^{-}$phrase accents that change the pitch range for a following boundary tone, then it is unclear whether to transcribe the boundary tone in the two utterances here as an upstepped low tone $\left({ }_{\mathrm{L}} \mathrm{L} \%\right.$, equivalent to Nibert's $\left.\mathrm{H}^{-} \mathrm{L} \%\right)$ or as a downstepped high tone (!H\%). Again, we proposed to adopt a very surface transcription of such cases using a mid tone (M\%) until we have the evidence we need to decide among the competing, more abstract analyses.

Two other aspects of the Venezuelan utterances in Figures 6 and 7 are noteworthy. The first is the contrast in the location where upstep begins to affect accent peaks. In Figures $6 \mathrm{~b}$ and $6 \mathrm{c}$, only the nuclear accent on mañana is upstepped relative to the preceding material. In Figure 7a, by contrast, the upstepped portion starts not at the final accent, but at número, which is in narrow focus in this context. ${ }^{6}$ And in Figure $7 \mathrm{~b}$, the upstepped region starts even earlier, in keeping with the narrow focus on dieron. The shape of the F0 contour after the upstep in Figure 7 is also relevant. The following pitch range is compressed as well as raised, so that there is only a small dip and rise for the $\mathrm{L}+\mathrm{H}^{*}$ accent on de vuelo in both utterances, and a somewhat more pronounced dip and rise for the $\mathrm{L}^{*}+\mathrm{H}$ accent on el número in Figure $7 \mathrm{~b}$. These differences among these utterances bears on the issues addressed in the next section.

6. We asked the speaker of these utterances (the second author of this paper) to listen to them again a year and a half after producing them. He interpreted the utterance in Figure $7 \mathrm{a}$ as conveying narrow focus on número, meaning something like 'You said they gave him the flight number, right, not the flight's arrival time?', whereas Figure 7b seems to convey narrow focus on dieron ('You said the airline gave him the flight number, right? They could tell which flight it was just from the arrival time?') 


\section{The domain of upstep (and downstep)}

Our comparison of interrogative contours across dialects suggested that there is a functional parallel between a local rise to the $\mathrm{H} \%$ boundary tone in the anticadencia (full rise) of Castilian Spanish, illustrated in Figure 6a, and a more global manipulation of backdrop pitch range in the Venezuelan Spanish system, illustrated in Figures $6 \mathrm{~b}$ through 7. Our comparison across utterances that convey different focus patterns in Figure 7 further shows that the domain of the Venezuelan interrogative upstep does not have to be limited to the accent in final position. Rather, the raised pitch range can affect peaks at least one and possibly two accents before the last accented word in the utterance. This fact raises three further questions. First, what is the formal difference between a shorter upstep domain, as in Figures $6 \mathrm{~b}$ and $6 \mathrm{c}$, and a longer one, as in the two utterances in Figure 7? Second, is the domain size independent of the phrasing, or is there some phrasal domain that functions as an edge for the upstep? Third, does the upstep that we posited for Castilian Spanish to explain the shape of the rise in Figure $3 \mathrm{c}$ show the same variability in domain, and if so, is the pragmatic function similar?

Different researchers have proposed different answers to these questions. Sosa $(1991,1999)$ models upstep as a raising of pitch range triggered by particular accent types. The domain of upstep is then all material after the pitch accent that triggers it. There is no relationship to a particular level of phrasing. Nibert (2000) models upstep as a raising of the pitch range triggered by a $\mathrm{H}^{-}$ phrase accent that raises the following boundary tone in an intonational phrase. The $\mathrm{H}^{-}$phrase accent (like the $\mathrm{L}^{-}$phrase accent that she posits to model the compression of accents in post-focal position in utterances such as Figures $3 \mathrm{a}$ and $3 \mathrm{~b}$ ) is associated with a lower-level prosodic unit intermediate between the intonational phrase and the word. Hualde (2000) also models upstep as a raising of the pitch range triggered by a $\mathrm{H}^{-}$phrase accent. However, his model differs from Nibert's in that the upstep also affects preceding accent peaks. The domain of upstep then is co-extensive with the intermediate phrase and not merely associated with its final edge.

The evidence for deciding among these analyses is not yet available. The arguments are complicated and require a careful sifting of assumptions. In particular, the issue of upstep (and downstep) domain needs to be separated from the issue of whether the upstep (and downtep) trigger is associated with the edge of an intermediate phrase. The Sp_ToBI group, therefore, opted for the most conservative compromise among these analyses. We do not choose either trigger, but mark upstep (and downstep) directly. We also do not provide for phrase accents, but leave gaps in the break indices, as we will describe below.

To give a flavor of the kinds of evidence that would speak to these issues, we review some of Nibert's arguments for the intermediate phrase. The ar- 
guments focus on differentiating between cases where there is an utterancemedial phrase boundary and cases where there is not, in minimal pairs such as (5), which shows her transcriptions of sample utterances by one of her Castilian Spanish speakers.

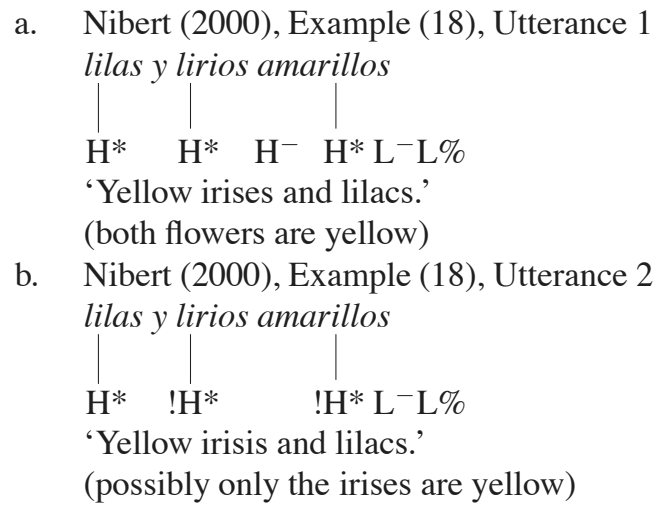

The pitch track for the utterance in $(5 b)$ shows the same pattern as in our Figure $2 \mathrm{~b}$, and the pitch track for the utterance in (5a) shows a pattern that is similar to that in our Figure 3c, with one small difference. As in le dieron el número in Figure 3c, there is a rising accent on lilas, followed by a small dip during $y$, then another rise in lirios which reaches a peak value within the stressed syllable which is about $8 \mathrm{~Hz}$ higher than the peak in lilas. The pattern differs from the contour in Figure $3 \mathrm{c}$ in that the pitch then levels off momentarily before rising another $13 \mathrm{~Hz}$. Nibert attributes this second rise to the $\mathrm{H}^{-}$tone target. She also found that the word-final syllable next to the purported intermediate phrase boundary in the (5a) type is on average longer than the same syllable in the (5b) type. In (5), for example, the syllable to be compared is the [rjos] of lirios. The combination of this final lengthening both with an accent rise that shows the alignment pattern typical of a nuclear accent and with a boundary pitch movement that cannot be accounted for by the pitch accent alone is strong evidence of some kind of intonational boundary here. However, Nibert does not look at minimal pairs contrasting the purported intermediate phrase boundary with a purported full intonational phrase boundary. Therefore, we cannot rule out an alternative interpretation that equates the boundary here with a full intonational phrase boundary, as in our Figure 1.

It would be interesting to compare the amount of final lengthening on lirios in a minimal triplet that includes a list such as lilas o lirios o narcisos as well as the two phrase types in (5). Figure 8 shows such a list intonation. There is a full rise on vuelo, in contrast to the half rise on hablado in Figure 1a. If the list production of lilas o lirios o narcisos shows the same extensive rise on 
lirios that we see on vuelo in Figure 8, and has even more final lengthening than in the (5a) type, then we might interpret the larger rise as a sequence of $\mathrm{H}^{-}$phrase accent and upstepped $\mathrm{H} \%$ boundary tone at a full intonational phrase, in contrast with just the $\mathrm{H}^{-}$phrase accent at the intermediate phrase boundary in (5a) and our Figure 3c. Nibert (2000) does include some examples of this listing contour type, in order to contrast a purportedly $\mathrm{H}^{-}$phrase accent with a purportedly $\mathrm{L}^{-}$phrase accent. Her examples are shown in (6), with her transcriptions.

a. Nibert (2000), Example (19), Utterance 3

¿Prefieres el libro de números o láminas?

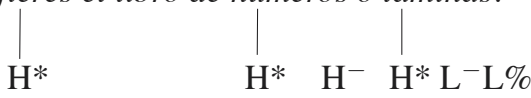

'Do you prefer the numerals book or the one of pictures?'

(exhaustive list)

b. Nibert (2000), Example (19), Utterance 4

¿Prefieres el libro de números o láminas?

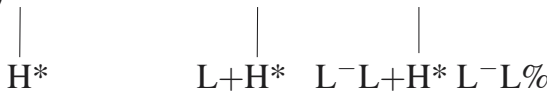

'Do you want the numerals book? Or pictures?'

(list not exhaustive)

The pitch track for the utterance in (6a) shows a rise of more than $50 \mathrm{~Hz}$ during the word numeros, which is quite similar to the rise in vuelo in our Figure 8. However, she transcribes this only as $\mathrm{H}^{-}$and not as a $\mathrm{H}^{-} \mathrm{H} \%$ sequence. Several other examples that she has transcribed in the same way (and which she includes in calculating the average syllable duration at the purported intermediate phrase boundary) also show this unexplained difference from utterances such as (5a). Some of these even had large pauses after the purported intermediate phrase boundary. A fact that is puzzling about Nibert's data is that there seemed to be a more pronounced final lengthening at intermediate phrases marked by $\mathrm{H}^{-}$than at intermediate phrases marked by $\mathrm{L}^{-}$. However, she shows only the average values and does not examine the full distribution of values within the two groups. Thus it is possible that the apparently greater final lengthening at boundaries marked with $\mathrm{H}^{-}$is an artifact of averaging over syllables that are final in an intermediate phrase (with only $\mathrm{H}^{-}$) and syllables that are final in a full intonational phrase (with a $\mathrm{H}^{-} \mathrm{H} \%$ sequence). Looking at the distribution of values - e.g., in a scatterplot of the extent of each rise as a function of the final syllable duration - would be more informative than comparing the average values for either measure.

In short, while there is much that is suggestive of one or more levels of potentially tonally marked prosodic units below the intonational phrase, the 


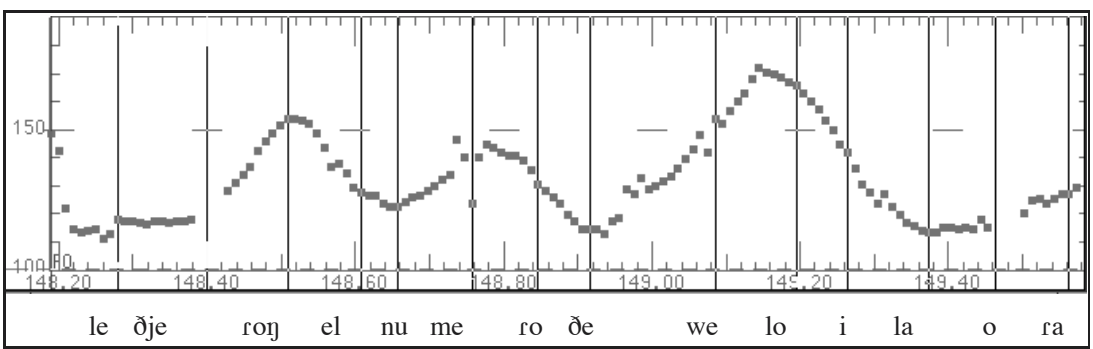

Figure 8. < md_ob6 $>$ Le dieron el número de vuelo y la hora (de salida) 'They gave her the flight number and departure time.' Response to ¿Qué pasó cuando llamó María al aeropuerto? 'What happened when Maria called the airport?' Speaker MD, Caracas.

evidence is not yet conclusive for even one dialect, much less for the Spanish system as a whole. Therefore, the Sp_ToBI group decided to begin by differentiating among only three types of juncture on the break indices tier. As in the original ToBI system for English, the default value for an "ordinary" inter-word juncture is 1 . The value 0 marks cases where there is clear segmental evidence of a closer inter-word juncture, such as the syllable reduction at the juncture between hubo and hablado in Figure 1. The value 4 marks cases where there is clear tonal and segmental evidence of some kind of intonational phrase break, such as the continuation rise and marked final lengthening at the boundary between hablado and Juan in Figure 1a. Marking these cases with 4 reserves index values 3 and 2 to mark one or two more prosodic units below the intonational phrase, if we can formulate more definitive criteria for distinguishing them from instances of the full intonational break that we mark with 4. In order to formulate such criteria, we need to reexamine existing data sets more carefully, using histograms, scatterplots, and regression analyses rather than averages and ANOVA. Also, we need to design and conduct other studies of the relationships among global trends such as downstep or the raised pitch of the Venezuelan questions, final lengthening and segmental allophony, and the local pitch shapes at candidate phrase boundaries. For example, we need to systematically compare and test the different predictions of Sosa's (1999), Nibert's (2000), and Hualde's (2000) accounts of upstep. We need to do this on a dialect-by-dialect basis, and not assume that if we can formulate definitive criteria for a particular level of prosodic grouping in one dialect that these criteria are applicable in all or in any other dialects. 


\section{The current set of Sp_ToBI annotation conventions}

In this paper, we have reviewed some of the literature on intonation across Spanish, and discussed several of the examples that we recorded and discussed together in our own effort to understand this literature and implement it in a consensus Sp_ToBI system. While the evidence for some of the tones and tonally marked prosodic structures in some dialects is clear, it is also clear that much work remains to be done before $\mathrm{Sp} \_\mathrm{ToBI}$ can become the standard communal resource that some of the older ToBI systems already are. We have raised far more questions than can be answered now or in the near future. At the same time, we hope that we have managed to convey the spirit of cautious enthusiasm with which we have approached this endeavor. We summarize by listing the preliminary set of conventions in (7), illustrating them with reference to the utterances that we have discussed in this paper. (See Mendoza-Denton 1999 and McGory and Díaz-Campos 2000a for further illustrations, with accompanying sound files.)

The Sp_ToBI system to date WORDS TIER:

- Make an ordinary orthographic transcription and segment the utterance into orthographic words, as in ToBI systems for other languages with alphabetic writing systems.

SYL TIER:

- Transcribe the segments, syllable by syllable. To make these labels portable across platforms, the transcription should be in some ASCII tag set, such as the SAMPA alphabet (Wells 1989). Until we have an automatic tool for aligning such a transcription automatically with the audio file, spend time on this tier just for syllables with potentially revealing segmental allophony - e.g., the devoiced dental fricative in the last syllable of universidad in Figure 4.

BREAK INDICES TIER:

- Mark subjective sense of disjuncture between each pair of words and before each pause, as in other ToBI systems. Distinguish among the following three levels:

$0 \quad$ any clear example of "syllabic reduction via vowel contact between words" - e.g., between hubo and hablado in Figure 1a

1 any other "ordinary" inter-word juncture - e.g., between Juan and se in Figure 1a 
- Reserve 2 and 3 for potential units with clear phonological markers and a sense of disjuncture intermediate between 4 and 1; candidates include intermediate phrase, tonic group, clitic group.

TONES TIER:

- Distinguish among the following three accent types:

$\mathrm{L}^{*}+\mathrm{H}$ late rising accent, with peak after the stressed syllable and valley toward the beginning (prenuclear accent in Mexican Spanish and some Peninsular varieties, focal accent in the Catalan-speaking region of Spain) or toward the middle of the stressed syllable (prenculear accent in at least some Caribbean varieties) - e.g., accent on dieron in Figures $2 \mathrm{a}$ and $2 \mathrm{~b}$

$\mathrm{L}+\mathrm{H}^{*}$ early rising accent, with peak during the stressed syllable (Peninsular varieties) or just after the end of the stressed syllable if the syllable is intrinsically short (Caribbean varieties) - e.g., accent on dieron in Figure $3 \mathrm{~b}$ and on alemana in Figure $5 \mathrm{~b}$

$\mathrm{H}+\mathrm{L}^{*}$ a clear fall from a preceding higher pitch onto lower pitch during the stressed syllable, starting at about the rhyme onset - e.g., accent on lengua in Figure 7

- When a syllable sounds accented, but is difficult to identify as one of the above three or its downstepped or upstepped counterpart, use one of the following as a place holder for later reanalysis after the inventory of tunes in the dialect is better understood:

$\mathrm{H}^{*} \quad$ a clear small peak during the accented syllable, at about the same level as a clear prior $\mathrm{L}^{*}+\mathrm{H}$, when the lack of a minimum cannot be attributed to upstep and undershoot - e.g., accent on mañana in Figure 6b

* the percept of accent on a syllable where the pitch shape is too ambiguous even for $\mathrm{H}^{*}-$ e.g., accent on número in Figure 3b

- Mark upstep and downstep directly on the accent, as in:

$\mathrm{L}^{*}+$ ! H downstepped variant of $\mathrm{L}^{*}+\mathrm{H}-\mathrm{e}$.g., accent on número in Figures $2 \mathrm{a}$ and $2 \mathrm{~b}$

$\mathrm{L}+! \mathrm{H}^{*}$ downstepped variant of $\mathrm{L}+\mathrm{H}^{*}-$ e.g., accent on vuelo in Figures $2 \mathrm{a}$ and $2 \mathrm{~b}$

$¡ \mathrm{~L}+\mathrm{H}^{*}$ upstepped variant of $\mathrm{L}+\mathrm{H}^{*}-$ e.g., accent on mañana in Figure 6c 
- Distinguish between the following two boundary pitch shapes:

$\mathrm{L} \%$ fall to a lower $\mathrm{F} 0$ after $\mathrm{L}+\mathrm{H}^{*}$, etc., or maintenance of a low $\mathrm{F} 0$ after $\mathrm{H}+\mathrm{L}^{*}$

$\mathrm{H} \% \quad$ rise to a higher $\mathrm{F} 0$ after any accent

- Do not choose prematurely between $i \mathrm{~L} \%$ and $! \mathrm{H} \%$ analyses for a dialect without an established tone inventory. Instead mark:

M\% half rise or mid-level plateau after a $\mathrm{L}+\mathrm{H}^{*}, \mathrm{H}^{*}$, etc.

MISC TIER:

- Tag such phenomena as hesitation pauses, dysfluencies, laughter, or anything else which complicates the analysis of the tone pattern and/or the phrasing. Also use this tier to keep track of alternative analyses that are proposed for the utterance.

CODE TIER:

- Identify the dialect (and sociolect) of the speaker, if known. Eventually, we hope to be able to use this tier to mark instances of intonational code switching as well.

Ohio State University

\section{References}

Alcoba, Santiago, and Julio Murillo (1999). Intonation in Spanish. In Intonation Systems: A Survey of Twenty Languages. Daniel Hirst and Albert Di Cristo (eds.), 152-166. Cambridge, UK: Cambridge University Press.

Arvaniti, Amalia, and Mary Baltazani (in press). Intonational analysis and prosodic annotation of Greek spoken corpora. To appear in Prosodic Typology and Transcription: A Unified Approach. Sun-Ah Jun (ed.). Oxford: Oxford University Press.

Beckman, Mary E.; Julia Hirschberg; and Stefanie Shattuck-Hufnagel (in press). The original ToBI system and the evolution of the ToBI framework. To appear in Prosodic Typology and Transcription: A Unified Approach. Sun-Ah Jun (ed.). Oxford: Oxford University Press.

Bolinger, Dwight L. (1958). A theory of pitch accent in English. Word 14: 109-149.

Bolinger, Dwight L. and M. Hodapp (1961). Acento melódico. Acento de intensidad. Boletín de Filología de la Universidad de Chile 13: 33-48.

Bruce, Gösta (1977). Swedish Word Accents in Sentence Perspective (Travaux de l'institute de linguistique de Lund 12). Lund: Lund University.

Contreras, Heles (1977). El orden de las palabras en español. Madrid: Cátedra.

Contreras, Heles (1980). Sentential stress, word order, and the notion of subject in Spanish. In The Melody of Language: Intonation and Prosody. L. R. Waugh and C. H. van Schooneveld (eds.), 45-53. Baltimore: University Park Press.

D'Imperio, Mariapaola (this issue). Italian intonation: An overview and some questions. Probus.

Face, Timothy L. (1999). Efectos segmentales del acento español. Boletín de Lingüística 14: 1832.

- (2001). Focus and early peak alignment in Spanish intonation. Probus 13: 223-246.

- (this issue). Contrastive focus and local intonation patterns in Spanish. Probus. 
Frota, Sónia (this issue). Nuclear falls and rises in European Portuguese: A phonological analysis of declarative and question intonation. Probus.

Garrido, Juan M., Joaquim Llisterri, Carme de la Mota, Rafael Marín and Antonio Ríos (1995). Prosodic markers at syntactic boundaries in Spanish. Proceedings of the 13th International Congress of Phonetic Sciences, 370-373.

Godjevac, Svetlana (2000). Intonation, word order, and focus projection in Serbo-Croatian. Doctoral dissertation, Ohio State University.

Grice, Martine; D. Robert Ladd; and Amalia Arvaniti (2000). On the place of phrase accents in intonational phonology. Phonology 17: 145-187.

Grimes, Barbara F. (2000). Ethnologue: Languages of the World. 14th ed. Electronic bibliographic index available at http://www.sil.org/ethnologue.

Gussenhoven, Carlos (2000). The boundary tones are coming: On the non-peripheral realisation of boundary tones. In Papers in Laboratory Phonology V. Michael Broe and Janet Pierrehumbert (eds.), 132-51. Cambridge, UK: Cambridge University Press.

Halliday, M. A. K. (1967). Notes on transitivity and theme in English. Journal of Linguistics 3: $177-274$.

Hualde, José Ignacio (2000). Intonation in Spanish and the other Ibero-Romance languages: Overview and status quaestionis. Paper presented at the 30th Linguistic Symposium on Romance Languages, Gainesville, FL, February 24-27, 2000. To appear in Romance Phonology and Variation: Selected Papers from LSRL 30, Caroline Wiltshire and Josquin Camps (eds.). Amsterdam: Benjamins.

Jun, Sun-Ah (ed.) (in press). Prosodic Typology and Transcription: A Unified Approach. Oxford: Oxford University Press.

Kvavik, Karen H., and Carroll L. Olsen (1974). Theories and methods in Spanish intonational studies. Phonetica 30: 65-100.

Ladd, D. Robert (1996). Intonational Phonology. Cambridge, UK: Cambridge University Press.

McGory, Julia Tevis, and Manuel Díaz-Campos (2000a). Sp_ToBI (Spanish Tones and Break Indices). Ms. available at: http://www.ling.ohio-state.edu/ $\sim$ tobi/sp-tobi/spanish.html

- (2000b). Declarative intonation patterns in multiple varieties of Spanish. Paper presented at the Fourth Hispanic Linguistics Symposium, Bloomington, IN, November 17-19, 2000.

Mendoza-Denton, Norma (1999). Minutes of the first Spanish Tones and Break Indices (Sp_ToBI) workshop. Ms. available online at http://www.ling.ohio-state.edu $/$ tobi/sp-tobi/minutes_ formatted.html

Morgan, Terrell A. (2000). Electronic Catalogue of the Sounds of Spanish. Multi-dialect speech corpus available online at http://sppo.ohio-state.edu/faculty/morgan.3/sounds.html

Navarro Tomás, Tomás (1918). Manual de pronunciación española. Madrid: Centro de Estudios Históricos.

- (1939). El grupo fónico como unidad melódica. Revista de Filología Hispánica 1: 3-19.

- (1944). Manual de entonación española. New York: Hispanic Institute in the United States.

Nibert, Holly Joy (2000). Phonetic and phonological evidence for intermediate phrasing in Spanish intonation. Doctoral dissertation, University of Illinois, Urbana-Champaign.

Peng, Shu-hui, Marjorie K. M. Chan, Chiu-yu Tseng, Tsan Huang, Ok Joo Lee and Mary E. Beckman (in press). A Pan-Mandarin ToBI. To appear in Prosodic Typology and Transcription: A Unified Approach. Sun-Ah Jun (ed.). Oxford: Oxford University Press.

Pierrehumbert, Janet B. (1980). The phonetics and phonology of English intonation. Doctoral dissertation, Massachusetts Institute of Technology.

Prieto, Pilar (1998). The scaling of the L tone line in Spanish down-stepping contours. Journal of Phonetics 26: 261-282.

Prieto, Pilar, Jan Van Santen and Julia Hirschberg (1995). Tonal alignment patterns in Spanish. Journal of Phonetics 23: 429-451.

Quilis, Antonio (1971). Caracterización fonética del acento español. Travaux de Linguistique et de Littérature 9: 53-72. 


\section{Mary E. Beckman et al.}

Sosa, Juan Manuel (1991). Fonética y fonología de la entonación del español hispanoamericano. Doctoral dissertation, University of Massachusetts, Amherst.

- (1999). La entonación del español: Su estructura fónica, variabilidad y dialectología. Madrid: Cátedra.

Välimaa-Blum, Riitta (1988). Finnish existential clauses - their syntax, pragmatics and intonation. Doctoral dissertation, Ohio State University.

Venditti, Jennifer Jeane (1997). Japanese ToBI labelling guidelines. Ohio State University Working Papers in Linguistics 50: 62-72.

Wells, John C. (1989). Computer-coded phonemic notation of the individual languages of the European community. Journal of the International Phonetic Association 19: 32-54.

Willis, Erik W. (2000). Pitch accent alignment of declarative sentences in Dominican and Mexican Spanish. Paper presented at the 29th Annual Meeting of the Linguistic Association of the Southwest,Puebla, Mexico, October 13-15, 2000. 